\title{
Buildings that teach: a strategy for sustainable design
}

\author{
M. Bahho ${ }^{1}$, B. Vale ${ }^{2} \&$ T. Milfont ${ }^{2}$ \\ ${ }^{1}$ ideaschool, Eastern Institute of Technology, Hawke's Bay, New Zealand \\ ${ }^{2}$ Victoria University of Wellington, New Zealand
}

\begin{abstract}
This paper discusses the engagement of groups from tertiary education and the building industry in the refurbishment of an existing log cabin on a university campus to function as a demonstration sustainable project. The paper describes the development of an interpretive and qualitative research model to uncover the complex factors behind behavioural influences. The research is a case study of creating, monitoring, and using a sustainable building, including a series of pre and post engagement interviews with those involved in the building, used to analyse why participants become engaged in the project, and as a consequence how their behaviour might change towards sustainability. Initial findings suggest 'action' is a significant moment where behaviour changes, as it creates a medium for learning new behaviour and abandoning the old. In this project action only increased as the project gained momentum. When the building was almost half finished people began to volunteer to be involved with it. The acceptance 'tipping point' or threshold came when there was enough physical reality that people could see becoming involved would produce something tangible. The results so far suggest that changing to sustainability stems from the initial involvement of a few highly motivated individuals but when there is sufficient physical reality and reduced psychological distance, more people become involved.

Keywords: sustainable building, demonstration project, psychological distance, threshold, tipping point.
\end{abstract}

\section{Introduction}

This paper describes the preliminary findings of an ongoing research project on a demonstration sustainable building. The overall focus of the research is on gathering experiences from the process of designing and building a demonstration 
sustainable building in order to discuss the motivation behind the different people involved in the project, and to see how their engagement changed as the project progressed. The project also looks at buildings that teach through displaying environmental practices and solutions as good examples of information choices to show to users and visitors, and to inspire behavioural change through how the building is used. A further aim is for those involved in the project to realise the effects of being part of it and to investigate whether their practical participation will steer their future choices.

The study is based on a real project involving an existing log cabin building at Otatara Hills, part of the Eastern Institute of Technology (EIT), Napier, New Zealand. It was built in 1986, and previously used as a staff office space for the Arts programme and as an artist-in residence living space. The site itself has strong historic, cultural, and spiritual associations with local indigenous Māori. It is now being converted into a sustainable demonstration facility for the community. Given the significant proportion of construction activity now related to refurbishment [1], the project is focused on displaying building refitting concepts and techniques. This produces two questions. Can a sustainable building project become a teaching tool through influencing behaviour of those involved in it? More importantly, when does support for a sustainable project cross a threshold towards environmental action? These questions are addressed in the present paper. We posit that three theoretical perspectives (threshold model, tipping point, and psychological distance) can help us understand the support of people engaged in creating a demonstration sustainable building.

\section{Theoretical models}

Granovetter's seminal work [2] established a model for collective behaviour to explain the way people change through setting up a pattern for individual decision making within a group. His idea was that each individual has a 'threshold' such that the decision to act is determined only if a proportion of others have already acted. The balance of costs and benefits determines the individual's preferences and eventual decision-making. Based on simple principles of aggregation, the model included a frequency distribution of thresholds allowing the calculation of an equilibrium number of individuals by which a specific decision may be made, fig. 1 . The analysis was intended to apply to any appropriate binary decision, and assumed that thresholds were distributed uniformly $\left(45^{\circ}\right.$ line). Granovetter maintained that such threshold models would be useful in small-group settings as well as those with large numbers of individuals, yet stressed that thresholds, being behavioural dispositions, are difficult to measure with confidence before the behaviour actually occurs. He also observed that a very small change in the distribution of preferences could generate a large difference in the outcome. Chiang [3] supported this argument using an extension of Granovetter's threshold model to investigate 'bandwagon' dynamics in social networks. He found that participation levels increase when network structures depart from pure homophily leading to further participation. Chiang affirmed that this principle is consistent with insights from other empirical studies. 


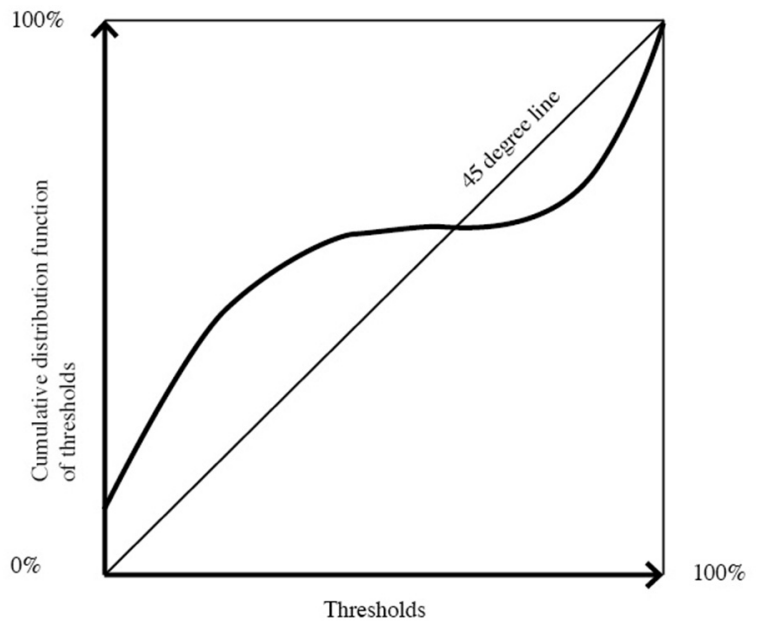

Figure 1: Graphic demonstration of the uniform distribution of thresholds and the equilibrium point of their distribution (Adapted from Granovetter [2] (fig. 1)).

Related to the threshold model, Gladwell [4] later defined a 'tipping point' as the moment of the emergence and spread of an idea or a change in social behaviour, thereby crossing a critical threshold and leading to its spread. Traditionally, the term has often been used in social rather than environmental sciences in order to define a phenomenon or rare event that becomes more common [5]. In particular, Gladwell stressed that changes that mark everyday life phenomena and social behaviour may start with one precisely targeted push, just like an epidemic; hence social changes occur suddenly rather than slowly as little causes can have big effects [4]. For a tipping point to occur, he classified three rules based on a way of understanding epidemics. First is the rule of the few, in theory the $80 / 20$ rule that a minority of people accounts for the majority of the phenomenon. Second is the stickiness factor, which addresses basic issues of successful communication and how to attract attention and make messages memorable and compelling. Third is the power of context, stressing the fact that people are sensitive to particular and topical issues caused by time and place.

Another related theoretical model for the present argument is Trope and Liberman's [6] Construal Level Theory (CLT) that examines psychologically distant objects or events. According to the theory, there are four main dimensions of psychological distance when people mentally represent objects/events not directly experienced in reality: temporal (time), spatial (physical space), social (interpersonal), and hypothetical (imagining that an event is likely or unlikely) [6, 7]. The general idea is that the more distant an object/event is from the individual, the more 'abstract' it appears, while the closer the object/event is, the more 'concretely' it will be thought of. Thus, more remote entities, such as places, people, objects and events, are represented more 'abstractly' than proximal 
entities. CLT also considers psychological distance to be a subjective experience of immediate surroundings, proposing that the various distance dimensions be anchored on a single reference point representing direct experience of the present. In a study of proximity to the coast in New Zealand and its link to climate change beliefs (and inherent sea-level rise), Milfont et al. [8] found that lower psychological distance (indexed by living nearer to the coast) was generally associated with higher levels of concern for climate change. Another related study observed that considering adaptation options to sea level rise, thus making the issue psychologically closer, influenced people's pro-environmental intentions [9].

The installation of wind turbines in the Hockerton Housing Project, Nottinghamshire, UK, provides a good illustration of how psychological distance influences environmental perceptions. This community project consisted of a terrace of five single story earth-sheltered dwellings in a rural setting that aimed to be self-sufficient in food, water, and energy. Based on that objective, groups of people were involved in the project from the beginning and were motivated to invest their own money in a low-environmental impact project. During the process of design and building, the group was able to withstand problems that arose on a number of occasions. In particular, they stood firm to overcome the initial resistance from the territorial authorities and other residents in the community to install the first of two wind turbines for the project [10]. At the beginning, the reality of installing the turbines was temporally distant and of uncertain results. After 4 years of trying to convince people the turbines would not have a negative effect, they were eventually installed. Later, after the psychological distance was decreased and people could see the minimal impact of the wind turbines, the other residents in the village of Hockerton decided to purchase and install a second-hand wind turbine in order to help lower carbon emissions in the local community, resulting in the production of more electricity than the village consumes. This example illustrates psychological distance (temporally distant and uncertain benefits of the wind turbines) as well as the threshold/tipping point of collective acceptance once uncertainty was reduced. This example also shows how certain values held in the community can inspire action, motivating others with similar values to initiate further projects in the same village to the benefit of all. As discussed below, similar processes seem to have emerged in our demonstration sustainable building.

\section{Method}

\subsection{Approach}

The primary purpose of this paper is to investigate whether taking part in the building process of a demonstration sustainable building can be a catalyst for influencing pro-environmental behaviour and whether the level of engagement changed as a direct result of taking part in it. An action research approach [11] was adopted as a strategy for introducing and promoting environmental knowledge and practices to the various groups engaged with the building project. This also 
allowed the researcher to learn from, and reflect on the proposed environmental practices.

\subsection{Participants}

This study, which is part of ongoing $\mathrm{PhD}$ research, investigates how opting to work (or not work) on the project correlates with environmental values before and after engagement with it. As the sustainable project yielded a chronology of events, the multiple sources of data from the various groups engaged in it were analysed for each phase. Examples of phases and groups are given below.

\subsubsection{Project concept design}

The opportunity to generate the design concept for the refurbishment was offered to a group of 19 Spatial Design students from EIT as part of their Second Year Studio Project. Six students chose to take part, the collective work of which formed the foundation for the design scheme, based on guidelines for the brief set by the first author.

\subsubsection{Sponsorship and sourcing}

Funds for the supply of construction materials and equipment needed for the building works were raised through sponsorship with no cost to the institution, due to a prior agreement. Groups and individuals involved included sponsors, suppliers, and project supporters. This paper deals with results from an interview conducted with three of the seven project sponsors: Independent Timber Merchants (ITM), who are supplying the building materials for the project; Gemco Group Holdings (GGH), who are contributing to the project build; and Unison Networks Ltd, who are supplying the photovoltaic energy generating system for it.

\subsubsection{Contribution to the build}

A portion of the project works was by students and staff of the Trades and Technology School at EIT as part of their 'work experience' practice. There were also contributions from a number of volunteer supporters from EIT and the community.

\subsubsection{Management support}

Once the project was close to completion, seven people were invited for a visit, separately or in groups of two. Upon witnessing the progress they decided to support it, in different capacities. The Head of EIT ideaschool and the Research Director at EIT were probed about their reasons for now supporting the project in separate interviews.

\subsection{Materials}

To examine the effectiveness of the project in influencing these psychological constructs, the research model uses a multi-phase case study employing a multi- 
method approach across a number of studies. These involve the various actors who chose to be involved in the project at different stages of the building process.

Specific questions were identified for the different actor groups directly related to their particular contribution or level of engagement. Each participant either took part in a focus group or an individual set of interviews pre and post-engagement, which were developed following an extensive literature review. For participating students, the focus groups consisted of four sections, however in relation to this paper, only one section is discussed as it focused on the individual's decision to take part in the project. For the sponsors, project supporters, and managers, the interviews were in three sections, one of which is discussed here as it deals with the reasons for the participant's 'engagement in this demonstration project'.

This paper thus examines the initial findings from focus groups and interviews with the four named groups and their involvement with the project so far: the project designers, sponsors, individuals involved in the construction, and management support.

\subsection{Data analysis}

The research adopted 'thematic analysis' techniques to examine the qualitative data and clarify the reasons for involvement in the project [12]. This analysis was done across questions, rather than for individual open-ended questions, in order to identify commonalities running through the data for each of the four groups.

\section{Results}

This section outlines findings from analysis of the contributions from various focus groups and interviews, with particular emphasis on the question: What was your motivation for taking part in this project? Transcripts of the discussions, which identified each participant's contribution, were used as the basis for the analysis.

\subsection{Project concept design}

All six students affirmed they engaged in the project in order to nurture their passion for and to seek in depth knowledge about environmental matters. Three students also decided to take part in the project as they wanted to care for nature and preserve natural resources, stating their reasons as for example, 'to help people be inspired by nature' and 'people need to start considering that, because we are draining our natural resources.' A fourth student was keen on working with recycled materials and wanted to do design based on recycling things such as 'lighting fittings.' The fifth student confirmed being enthused by the project and commented, 'I've always had an underlying passion for sustainability, but I thought it is a bit hard...the log cabin inspired my passion.' The sixth student aimed to improve the environmental performance of their own residence and hoped to learn more technical information but noting 'solar panels are an absolute must.' 


\subsection{Sponsorship and sourcing}

Three of the project sponsors were interviewed. In general, their main motivation was related to business benefits. Two stated the reason for sponsoring the project was the personality and enthusiasm of the researcher (who explained the project in asking for sponsorship), one saying 'it was a fantastic sale's pitch'. The third stressed 'this is one of those areas that we should be assisting to lead; the perception, the education, the training of sustainability,' and affirmed the company's desire to become a leader in the market. In addition, this sponsor also stated, 'the big reason for me wanting to be involved here...is seeing it as an opportunity... of learning something about it for ourselves.' The first sponsor emphasised the importance for the company to support such a project explaining, 'very keen to understand the impact of emerging technologies including sustainable ones...to get a lot of existing readings from' referring to generated PV outputs energy readings. That same sponsor showed commitment by wanting 'to demonstrate our interest in that area and our keenness in an innovation space,' as well as mentioning having a strong relationship with EIT, as a factor. The third sponsor felt the idea of the project was of interest adding, 'we thought it was for a good cause.' The same sponsor also mentioned the established work relationship with EIT as a contributing factor. It was observed that it was easier for the third sponsor to be convinced to come on board knowing that the project had attracted the first two sponsors. This was a critical leverage point.

\subsection{Contribution to the building work}

The students at the Trades and Technology School at EIT contributed to the building work as part of their 'work experience' course requirements. A focus group of two student participants and a tutor was conducted. The tutor was motivated by the ecological objectives of the project that correlated with the attitude of 'care' for the environment explaining, 'It is a small scale, but it is about education, and, you know, putting it out there.' The tutor continued, 'As an individual, I care, and as soon as you get that factor in it, people start to buy into it, and all of a sudden, we are healing the world.' Both student participants were keen on recycling, one stating, 'certain stuff that you recycle, you can use again, which keeps the environment clean by using less resources.' The second commented, 'the project opened my eyes to a different type of building.' The student continued, 'Recycling, my mum taught me to recycle, and why recycle.'

Another focus group with two technicians who contributed to the project build was conducted. When asked about their motivation, the first saw it as a matter of helping someone in need stating, 'for me, when you turned up with all these windows for the greenhouse, I looked up at this daunting task and had to tidy them up.' The second agreed to help when asked by the manager affirming, 'you see a need and you do it.' Commenting on personal views upon seeing the type of project, the same technician stated, 'If it was something damaging to the environment, I wouldn't get involved' Also, commenting on personal feelings when the project started taking shape, 'you can see the vision more clearly when there is something happening there, and it is more interesting.' Both technicians 
emphasised the significance of taking action in terms of the practical engagement with environmental tasks. On that subject, the first recounted individual experience when the institution was planning to have a sustainable building on campus in 1986 stating, 'I have always been interested in sustainable technologies...I went to one of those meetings, and it ended up being a big talk about anything other than putting a windmill or a sort of wind generator, but that is all I was interested in, the hands on side of it, something that would generate power.' The second technician reflected that idea describing his experience in relation to the $\log$ cabin project, 'Sustainability is often something that is talked about a lot and you read about it in other places, but it is great to see it do-able in your backyard. That could be a reason why I decided to continue helping you.'

\subsection{Management support}

Two of the managers at EIT were interviewed separately. Initially, both were motivated to back the project as part of their management role. However, as the project gained momentum and started to take shape, other motivations emerged. For the first, the fact that it was a sustainable building influenced the decision to support it emphasising that 'it is important that everything we do from here on in has got that in mind because the world has changed.' However, when the building started to take shape, it was realised that it would fit the institution's plans to redevelop the site, 'We had an interest in redeveloping Otatara to reflect the importance it has had to the Art School and within EIT. I saw it as probably an anchor point for that redevelopment.' The project's objectives of using it as a place, 'where you can take schools to learn about sustainability... and the idea of an artist-in-residence accommodation' made the project more appealing, 'now it is extremely important to finish it off, really.' The second manager was personally involved in certain building activities and donated materials stating, 'I think the project itself is great in terms of the concept and what you want to do with it.' Following an earlier visit to the site, this manager was motivated to assist with the building activities because, 'a lot of it is done on donations or cut-rate services from other people. I thought, well, I have got a little bit of useful experience at times...that could be useful as well.' This manager was also influenced by the sustainable qualities of the project, emphasising, 'I think sustainable buildings are a good idea, but they don't seem, to my limited understanding...to be made to seem do-able to a lot of people.' So to take a building that, 'was probably close to being derelict and turning it into something that is useful, sustainable, and green was inspiring.'

\section{Discussion}

This paper has briefly examined the motivations of various participating parties involved in the demonstration sustainable building project. The analysis shows that the motivations of these various parties differ according to the balance between costs and benefits, which in turn determine an individual's decision making - a finding supported by Granovetter's threshold model [2]. For the student designers, the main benefit was to fulfil their passion for nature and 
ecology, especially when their interests were focused on a real project, which made the knowledge learned more relevant. On the other hand, for the sponsors, business benefits and having a commercial edge over competitors was the main motivation for taking part. As mentioned before, once the first two sponsors were on board, it was easier to persuade others to participate.

For the EIT staff, the fact that they decided to take part in the project sometimes without being asked was highly significant. That attitude coincided with the temporal momentum the project works gained when they were sufficiently complete for the project to seem 'real', which made the benefits of engaging seem worthwhile from the view of feeling good. A similar observation could be made with regard to management staff. It is worth mentioning that other staff members, not included in this study, have also expressed their willingness to take part at this later stage in the project.

According to Gladwell [4], there are three rules for a tipping point to occur and a message to cross a threshold. Applying them to this study, the first rule (the law of the few, where the success of any kind of initiative is dependent on the involvement of people with particular set of leadership and social skills) is shown by the first author, an EIT staff member, who took a hands-on approach, giving a lot of time and energy outside work hours to the project. In doing so he was leading from the front. As well, there was a team of 6 out of a total group of 19 design students who were sufficiently motivated to take part in the design of the project refurbishment. The same observation can be made with regard to the contribution of EIT technical staff and the first two sponsors. The second rule (the stickiness factor) highlighted the manner in which information about the project and its objectives was packaged. Under the right circumstances it became irresistible for sponsors and later for EIT management to respond positively to taking part because others were doing so. The third rule (the power of context, where the ideas embodied in the project were sensitive to the conditions and circumstances of the time and place) perhaps emerges as a testimony of the power of one specific aspect of context, sustainability, which was critical for many in the community. These three rules were identified in the data reported here in table 1. Moreover, and because the project was part of an education institution, it gave the project status and a place that related to teaching values. This was a main threshold (or motivating factor) for almost all participants in the project.

As the project gained momentum, it became more acceptable for people to volunteer to become involved. From our analysis, the acceptance threshold or tipping point came when there was enough physical reality emerging from the building work and people could see that becoming involved would produce something tangible. Therefore, it seems that the threshold emerged when the reality of the building became psychologically close [6]. At first, the reality of the refurbished building was temporally distant and uncertain, resulting in passivity or inaction. The refurbishment process then made the project visually present, certain, and temporally near to the people concerned, reducing psychological distance and promoting active action (fig.2). This is in line with recent research showing that motivation to act pro-environmentally increases when psychological distance decreases [8]. 
Table 1: An outline of Gladwell's three rules for achieving a tipping point, as applied to this study.

\begin{tabular}{|c|c|c|c|c|c|}
\hline & \multirow{2}{*}{$\begin{array}{l}\text { Design } \\
\text { Students }\end{array}$} & \multirow[t]{2}{*}{ Sponsors } & \multicolumn{2}{|c|}{ Building contributors } & \multirow[t]{2}{*}{ Management } \\
\hline & & & Students & Staff & \\
\hline $\begin{array}{l}\text { Law of the } \\
\text { few }\end{array}$ & $\mathbf{\square}$ & [ & & 口 & \\
\hline $\begin{array}{l}\text { Stickiness } \\
\text { factor }\end{array}$ & & $\mathbf{\square}$ & & & $\mathbf{\square}$ \\
\hline $\begin{array}{l}\text { Power of } \\
\text { context }\end{array}$ & [ & 口 & 口 & a & $\square$ \\
\hline
\end{tabular}

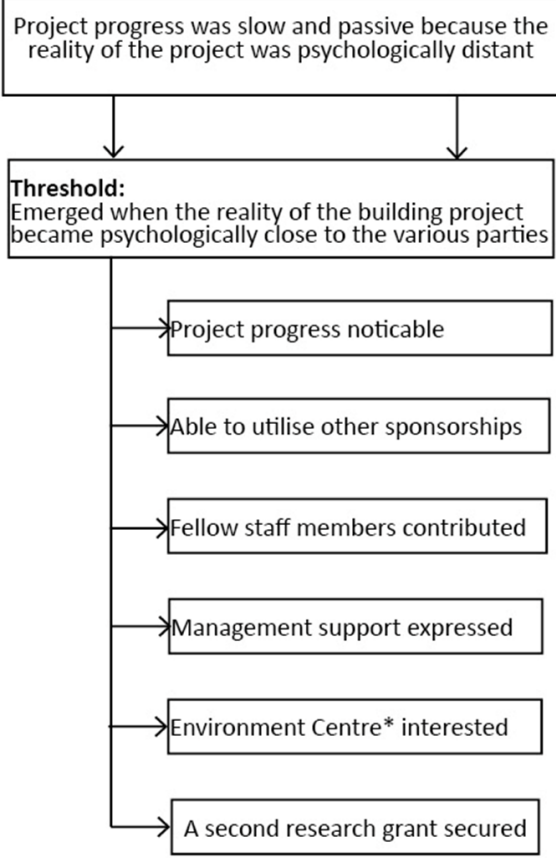

Figure 2: A tipping point for project engagement came when there was enough physical reality to reduce the psychological distance of the demonstration sustainable building project. (*The Environment Centre is a local group who want to rent the finished building for meetings.) 


\section{Conclusions}

Initial findings from this ongoing research suggest that motivation to engage in a demonstration sustainable building project increases after a threshold/tipping point of engagement is reached, which coincides with a perceived reduction of psychological distance. In this case, as the project gained momentum and become psychologically closer (i.e., physically present, and its completion and benefits temporally closer and more certain) it became more acceptable for people to be involved in it. At the early stages of the build, the reality of the refurbished building was temporally distant and uncertain, resulting in passive or non-action. The refurbishment process then made the project visually present, certain, and temporally near to those involved, reducing psychological distance, promoting active action, and increasing voluntary engagement. A similar process was also observed in the introduction of wind turbines in the Hockerton Project in the UK, as noted above.

In conclusion, we observed that in order to move people to become more sustainable, it is essential for them to be doing something that others can see in relation to issues of sustainability, especially sustainable buildings. When people witness the physical results of that work, they are more prepared to join in, and this seems to spill over to other parties. Therefore 'action' is a significant moment where behaviour changes as it creates a medium for learning a new behaviour and abandoning the old. This is important for moving to a sustainable built environment. We need sufficient sustainable buildings for people to consider that these are tangible and close (reducing psychological distance) so that they to want to live and work in sustainable buildings.

\section{References}

[1] SCMT, Working Group Sustainable Construction Methods \& Techniques Final Report 3/11/2003 - Contract Number: B43050/2003/352567/ SER/B4, 2004.

[2] Granovetter, M., Threshold models of collective behavior. AJS, 83 (6), pp. 1420-1443, 1978.

[3] Chiang, Y-S., Birds of moderately different feathers: Bandwagon dynamics and the threshold heterogeneity of network neighbors. Journal of Mathematical Sociology, 31, pp. 47-69, 2007.

[4] Gladwell, M., The tipping point: How little things can make a big difference. New York: Back Bay Books, 2002.

[5] Nuttall M., Tipping points and the human world: Living with change and thinking about the future. $A M B I O, 41$, pp. 96-105, 2012.

[6] Trope Y. \& Lieberman L., Construal-Level Theory of psychological distance. Psychological Review, 117 (2), pp. 440-463, 2010.

[7] Lieberman L., Trope Y., \& Stephen E., Psychological Distance at Social Psychology: Handbook of Basic Principles (2nd Edition) edited by Arie W. Kruglanski \& Edward Tory Higgins, 2007. 
[8] Milfont T. L., Evans L., Sibley C. L., Ries J. \& Cunningham A., Proximity to coast is linked to climate change belief. Plos One, 9 (7), pp. 1-8, 2014.

[9] Evans, L., Milfont, T. L., \& Lawrence, J., Considering local adaptation increases willingness to mitigate. Global Environmental Change, 25, pp. 69-75, 2014.

[10] Vale, B. \& Vale, R., The Hockerton Housing Project, England. In Vale R. \& Vale B. (eds), Living within a fair share ecological footprint, Oxon, England: Routledge, pp. 262-274, 2013.

[11] Elfors, S. \& Svane, Ö., Action research for sustainable housing: theoretical and methodological implications of striving for research as a tool for change. The Journal of Transdisciplinary Environmental Studies, 7(2), pp. 1-12, 2008.

[12] Braun, V. \& Clarke, V., Using thematic analysis in psychology. Qualitative research in psychology, 3 (2), pp. 77-101, 2006. http://dx.doi.org/10.1191/ 1478088706qp063oa. 